\title{
Erratum to: Chemical contamination in upper horizon of Haplic Chernozem as a transformation factor of its physicochemical properties
}

\author{
Tatiana M. Minkina ${ }^{1}$ - David L. Pinskii ${ }^{2}$ Inna V. Zamulina ${ }^{1}$ - Dina G. Nevidomskaya ${ }^{1}$. \\ Coşkun Gülser ${ }^{3} \cdot$ Saglara S. Mandzhieva $^{1}$ - Tatiana V. Bauer ${ }^{1}$ - Igor V. Morozov ${ }^{1}$ • \\ Svetlana N. Sushkova ${ }^{1} \cdot$ Ridvan Kizilkaya $^{3}$
}

Published online: 7 June 2017

(C) Springer-Verlag Berlin Heidelberg 2017

Erratum to: J Soils Sediments

DOI 10.1007/s11368-017-1713-5

The fifth author's name was incorrectly spelled. The correct author name should read Coşkun Gülser.

The original article was corrected.

The online version of the original article can be found at http://dx.doi.org/ 10.1007/s11368-017-1713-5

Tatiana M. Minkina

msaglara@mail.ru

1 Southern Federal University, 194/1, prosp. Stachki, Rostov-on-Don 344090, Russia

2 Institute of Physicochemical and Biological Problems of Soil Science, Russian Academy of Sciences, 2, st. Institutskaya, Pushchino 142290, Russia

3 Faculty of Agriculture, Department of Soil Science and Plant Nutrition, Ondokuz Mayss University, 55139 Samsun, Turkey 